\title{
Commentary: White matter injury and heart surgery-Will we get to the heart of the matter?
}

Phillip S. Naimo, MD, a,b,c and Igor E. Konstantinov, MD, PhD, FRACS ${ }^{\mathrm{a}, \mathrm{b}, \mathrm{c}, \mathrm{d}}$

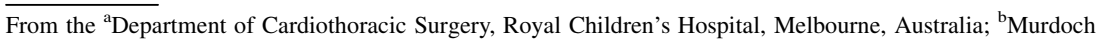
Children's Research Institute, Melbourne, Australia; ${ }^{c}$ University of Melbourne, Melbourne, Australia; and dMelbourne Children's Centre for Cardiovascular Genomics and Regenerative Medicine, Melbourne, Australia.

Disclosures: Authors have nothing to disclose with regard to commercial support.

Received for publication March 20, 2019; accepted for publication March 21, 2019; available ahead of print April $26,2019$.

Address for reprints: Igor E. Konstantinov, MD, PhD, FRACS, Royal Children's Hospital, Flemington Rd, Parkville 3052, Australia (E-mail: igor.konstantinov@rch.org.au).

J Thorac Cardiovasc Surg 2019;158:878-9

$0022-5223 / \$ 36.00$

Crown Copyright $\odot 2019$ Published by Elsevier Inc. on behalf of The American Association for Thoracic Surgery https://doi.org/10.1016/j.jtcvs.2019.03.069

It appears that the understanding of cerebral blood circulation has been evolving for centuries. Physicians have been aware of blood flow to the brain since approximately 2800 BCE; however, it was not until 1762 CE that investigation into the physiology of cerebral blood flow commenced. ${ }^{1}$ Finally, in the mid-1900s, Kety and Schmidt ${ }^{2}$ reported the first quantitative measure of cerebral blood flow. Since then, there has been a dramatic increase in research on cerebral blood physiology, and a number of noninvasive measurement techniques have been developed. Of particular interest in recent years has been the mechanism of white matter injury during neonatal and infantile cardiac surgery.

In a thought-provoking and thorough study published in the current issue of the Journal, Claessens and colleagues ${ }^{3}$ report that there was no correlation between cerebral oxygenation or cerebral autoregulation and postoperative white matter injury. There have been several methods used as a proxy to measure cerebral autoregulation. In the study of Claessens and colleagues, ${ }^{3}$ cerebral oxygenation was measured by near-infrared spectroscopy and correlated with mean arterial blood pressure to give an estimation of cerebral autoregulation. Although near-infrared spectroscopy appears to be a useful tool in measuring cerebral oxygenation, care must be taken in interpreting results, because several factors may affect measurements. First, near-infrared spectroscopy will represent a mixed oxygen saturation, of which $75 \%$ is determined by venous saturation, ${ }^{3}$ and thus it may be affected in cyanotic heart conditions. In addition, factors as simple as sensor placement or fluid retention may also alter results. ${ }^{4}$ Although no direct correlation has been demonstrated in this prospective study, it is an important step in our understanding of perioperative white matter injury.

It appears that neonatal cerebral vasculature and autoregulatory systems are underdeveloped, and even more so in neonates with congenital heart defects. ${ }^{5,6}$ In some

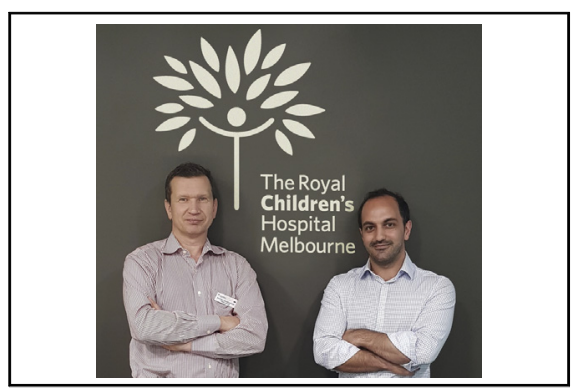

Igor E. Konstantinov, MD, PhD, FRACS (left), and Phillip S. Naimo, MD, BSc (right)

Central Message

There is no direct correlation between cerebral oxygenation or autoregulation and white matter injury after congenital cardiac surgery.

See Article page 867

patients, autoregulatory systems may not be functioning, and passive cerebral perfusion is not uncommon. ${ }^{7}$ Although studies have shown new white matter injury in $30 \%$ to $60 \%$ of neonates undergoing cardiac surgery, ${ }^{5}$ it is important to recognize that $20 \%$ to $40 \%$ of injury may occur preoperatively. ${ }^{5,8,9}$ The direct correlation of white matter injury with cardiac surgery thus remains elusive.

Although this prospective study of Claessens and colleagues $^{3}$ failed to find any correlation, it did not fail in its purpose. We would like to sum up with a famous statement that often is attributed to Thomas A. Edison, "I have not failed. I have just found 10,000 ways that won't work." Indeed, once again we see no clear correlation between cerebral oxygenation or cerebral autoregulation and white matter damage after cardiac surgery.

\section{References}

1. Bell BA. A history of the study of cerebral circulation and the measurement of cerebral blood flow. Neurosurgery. 1984;14:238-46.

2. Kety SS, Schmidt CF. The determination of cerebral blood flow in man by use of nitrous oxide in low concentrations. Am J Physiol. 1945;143:53-66.

3. Claessens NHP, Jansen NJG, Breur JMPJ, Algra SO, Stegeman R, Alderliesten T, et al. Postoperative cerebral oxygenation was not associated with new brain injury in infants with congenital heart disease. J Thorac Cardiovasc Surg. 2019;158: 867-77.e1.

4. Buratto E, Horton S, Konstantinov IE. So near, yet so far: is isolated cerebral nearinfrared spectroscopy in neonates nearly as useful as it is noninvasive? J Thorac Cardiovasc Surg. 2017;154:1054-5.

5. Andropoulos DB, Hunter JV, Nelson DP, Stayer SA, Stark AR, McKenzie ED, et al. Brain immaturity is associated with brain injury before and after neonatal cardiac surgery with high-flow bypass an cerebral oxygenation monitoring. J Thorac Cardiovasc Surg. 2010;139:543-56. 
6. Votava-Smith JK, Statile CJ, Taylor MD, King EC, Pratt JM, Nelson DP, et al. Impaired cerebral autoregulation in preoperative newborn infants with congenital heart disease. J Thorac Cardiovasc Surg. 2017;154:1038-44.

7. Soul JS, Hammer PE, Tsuji M, Saul JP, Bassan H, Limperopoulos C, et al. Fluctuating pressure-passivity is common in the cerebral circulation of sick premature infants. Pediatr Res. 2007;61:467-73.
8. Dent CL, Spaeth JP, Jones BV, Schwartz SM, Glauser TA, Hallinan B, et al. Brain magnetic resonance imaging abnormalities after the Norwood procedure using regional cerebral perfusion. J Thorac Cardiovasc Surg. 2005;130:1523-30.

9. Mahle WT, Tavani F, Zimmerman RA, Nicolson SC, Galli KK, Gaynor JW, et al An MRI study of neurological injury before and after congenital heart surgery Circulation. 2002;106(12 Suppl 1):109-14. 